\title{
EVALUASI PROGRAM SCHOOL FOR PRINCIPAL (SPc) SEKOLAH GURU INDONESIA (SGI)
}

\author{
Jejen Musfah ${ }^{1}$, Upi Rahmawati ${ }^{2}$ \\ ${ }^{1}$ Lecturer at Educational Management Departement Faculty of Educational Science (FITK) \\ Syarif Hidayatullah State Islamic University Jakarta. \\ ${ }^{2}$ Student of Educational Management Departement, Faculty of Educational Science (FITK) \\ Syarif Hidayatullah State Islamic University Jakarta. \\ jejen@uinjkt.ac.id \\ upirahmawati.sgi21@gmail.com \\ Received: 08/10/2018, Accepted: 20/02/2019, Published: 25/02/2019
}

\begin{abstract}
This study aims to evaluate the training program School For Principal (SPc) School of Indonesian Teachers (SGI) Dompet Dhuafa. SPc is one of the SGI programs that focuses on improving the Principal's competence. Non-formal training programs under the auspices of Dompet Dhuafa Coorporate University are held once a week for three months. This qualitative research uses case study on SPC Pandeglang, Banten region by using CIPP model (Context, Input, Process, Product). Research subjects were SGI head, facilitator and SPc participant of Pandeglang Region, Banten. Meanwhile, this activity was attended by 28 principals spread in 12 sub-districts of Pandeglang Banten region, consisting of 16 elementary schools (SD) and 11 Madrasah Ibtidaiyah (MI). The results showed: In the context of Context indicates that the training has been in accordance with the needs of the participants. In the input aspect, the training materials as needed, methods are relevant, order and values are already entrenched. In the aspect of the process indicates the suitability between planning and program implementation. While the product aspect shows that the value obtained by the participants is good. In addition, from the results of CSI (Costumer Satisfaction Index) shows a high level of satisfaction with the program. Thus, this program can be continued to improve the quality of Head of School and Head of Madrasah.
\end{abstract}

Kayword: school for principal, program evaluation, CIPP, principal/madrasah.

\begin{abstract}
ABSTRAK
Penelitian ini bertujuan untuk mengevaluasi program pelatihan School for Principal (SPc) Sekolah Guru Indonesia (SGI) Dompet Dhuafa. SPc merupakan salah satu program SGI yang berfokus pada peningkatan kompetensi kepala sekolah. Program pelatihan nonformal yang berada di bawah naungan Dompet Dhuafa Coorporate University ini diadakan setiap pekan sekali selama tiga bulan. Penelitian kualitatif ini menggunakan studi kasus pada SPe wilayah Pandeglang, Banten dengan menggunakan model CIPP (Context, Input, Process, Product). Subjek penelitian adalah kepala SGI, fasilitator, dan peserta SPe wilayah Pandeglang Banten. Adapun kegiatan ini diikuti oleh 28 kepala sekolah yang tersebar di 12 kecamatan wilayah Pandeglang Banten, terdiri dari 16 Sekolah Dasar (SD) dan 11 Madrsah Ibtidaiyah (MI). Hasil penelitian menunjukkan: Pada aspek Contect menunjukkan bahwa pelatihan telah sesuai dengan kebutuhan para peserta. Pada aspek input, materi pelatihan sesuai dengan kebutuhan, metode sudah relevan, tata tertib dan nilai-nilai sudah membudaya. Pada aspek process menunjukkan adanya kesesuaian antara perencanaan dengan pelaksanaan program. Sedangkan aspek product menunjukkan bahwa hasil nilai yang diperoleh peserta adalah baik. Selain itu, dari hasil CSI (Costumer Satisfication Index) menunjukkan tingkat kepuasan yang tinggi terhadap program. Dengan demikian, program ini dapat dilanjutkan untuk memperbaiki mutu kepala sekolah dan kepala madrasah.
\end{abstract}




\section{A. PENDAHULUAN}

Pendidikan yang belum merata di berbagai tempat masih menjadi permasalahan dunia pendidikan Indonesia. Kesenjangan ini terlihat baik pada jenjang pendidikan dasar maupun menengah. Hal ini dapat dilihat dari ketidakmerataan nilai Ujian Nasional. Sekolah di perkotaan cukup mendominasi jika dibandingkan dengan sekolah di pinggiran. ${ }^{1}$ Hal yang sama juga terjadi pada kualitas guru Indonesia. Kepala Badan Pengembangan Sumber Daya Manusia Pendidikan dan Peningkatan Mutu Pendidikan Kementerian Pendidikan dan Kebudayaan, mengakui bahwa masih banyak guru terutama di daerah-daerah yang tidak lulus uji kompetensi dan sertifikasi. Kondisi kualifikasi akademik guru juga masih rendah, dari 2,92 juta guru baru sekitar $51 \%$ berpendidikan S1 sedangkan sisanya belum. Dari program sertifikasi guru, hanya 2,06 juta atau $70,5 \%$ guru yang memenuhi syarat, sedangkan 861,67 guru lainnya belum memenuhi syarat sertifikasi.

Hasil Uji Kompetensi Guru 2015, distribusi kemampuan rata-rata guru dari urutan terbaik yaitu Jawa, Sumatra, Kalimantan, Sulawesi, Nusa Tenggara, Maluku, dan Papua. $^{2}$ Chairunnisa mengatakan, perlu adanya kebijakan persebaran guru-guru berkualitas, karena melihat persebaran guru berkualitas hanya berada di sekolah perkotaan favorit. Beberapa fenomena tersebut menunjukkan bahwa kualitas pendidikan Indonesia masih rendah. $^{3} \quad$ Beberapa permasalahan yang dihadapi sebagian besar pendidik di

\footnotetext{
Pupuh Fathurrohman. (2012). Guru Profesional. Bandung: Refika Aditama. hlm. 5.

${ }^{2}$ Ratih Hurriyati. (2016). Kualitas Guru Kita. Pikiran Rakyat, diakses 15 Januari 2017.

3 Connie Chairunnisa. (2016). Manajemen Pendidikan dalam Multi Perspektif. Jakarta: PT RajaGrafindo Persada. hlm. 292.
}

antaranya ialah budaya berpikir yang masih imitatif dan prosedural. Dengan demikian tidak tercipta kemandirian dan keunggulan komunitas pendidik. ${ }^{4}$

Sekolah memiliki peran penting sebagai wadah dalam pembentukan sumber daya manusia yang berkualitas. Sekolah harus mampu berperan aktif sebagai agen perubahan, yang mampu mendidik dan mencetak generasi cerdas di masa mendatang. ${ }^{5}$ Namun tidak semua sekolah mampu menjadi tempat yang tepat dan efektif dalam memperbaiki mutu SDM. Keberhasilan dalam memperoleh mutu pendidikan yang baik akan sangat bergantung pada kepemimpinan yang kuat. Kepemimpinan menurut Robbins, kemampuan untuk mempengaruhi suatu kelompok dengan tujuan untuk mencapai visi yang telah ditetapkan bersama. ${ }^{6}$

Salah satu faktor yang berperan dalam keberhasilan kinerja guru adalah kemampuan manajerial kepala sekolah, sebagaimana hasil penelitian Gemnafle, bahwa kompetensi manajerial memberikan kontribusi $33,79 \%$ terhadap kinerja guru. ${ }^{7}$ Namun, salah satu penyebab rendahnya mutu pendidikan Indonesia adalah dampak dari bentuk kepemimpinan kepala sekolah dalam mengelola sekolah. Peran dan

4 Tatang Suratno. (2014). Konstrutivisme, Konsepsi Alternatif, dan Perubahan Konseptual dalam Pendidikan IPA. Jurnal Pendidikan Dasar. No. 10 Oktober 2014. hlm. 1.

${ }^{5}$ H.A.R. Tilaar. (2012). 10 Windu Pendidikan Nasional: Arah ke Mana. Jakarta: PT Kompas Media Nusantara. hlm. 34.

6 S. Robbins (2015). Perilaku Organisasi. Jakarta: Salemba Empat. hlm. 249.

${ }^{7}$ Umammah. (2009). Pengaruk Kepemimpinan dan Keterampilan Manajerial kepala Sekolah Terhadap Kinerja Guru se-Kabupaten Malang. Malang: UIN Press. hlm. 11. 
tugasnya akan mempengaruhi semua aspek kehidupan sekolah. ${ }^{8}$

Direktorat Peningkatan Mutu Pendidikan dan Tenaga Kependidikan Departemen Pendidikan Nasional tahun 2008, setelah melakukan uji kompetensi memperkirakan bahwa $70 \%$ dari 250.000 kepala sekolah di Indonesia tidak kompeten. ${ }^{9}$ Banyaknya kepala sekolah yang kurang memenuhi standar kompetensi disebabkan kurang baiknya proses rekrutmen kepala sekolah.

Rata-rata kepala sekolah kurang memiliki kemampuan akademik, kurang memiliki motivasi diri, dan disiplin kerja, serta memiliki wawasan kependidikan yang sempit. ${ }^{10}$ Akhirnya berdampak pada rendahnya produktivitas kepala sekolah dalam meningkatkan kualitas pendidikan. Batas minimal uji kompetensi kepala sekolah yang dilakukan di 31 provinsi ialah 76. Namun ternyata beberapa kompetensi, seperti manajerial, dan wirausaha, supervisi, dan sosial masih rendah, secara berurutan: 74,72 dan $63 .^{11}$ Upaya yang dilakukan dalam memberdayakan kepala sekolah agar memiliki kecakapan dan kemampuan dalam menjalankan tugasnya ialah dengan pendidikan dan pelatihan.

Berbagai kendala kepemimpinan, pelatihan yang masih kurang, dan peran pelatihan dalam peningkatan kompetensi kepala sekolah, adalah alasan yang kuat

\footnotetext{
${ }^{8}$ Ginting dan Haryati. (2012). Kepemimpinan dan Konteks Penigkatan Mutu Pendidikan. Jurnal Ilmiyah CIVIS. Vol. II, hlm. 11. Lihat juga Uhar Suharsaputra. (2016). Kepemimpinan Inovasi Pendidikan. Bandung: Refika Aditama. hlm. 351.

${ }^{9}$ Tempo, edisi Selasa 12 Agustus 2008.

10 Nurdin Hidayat. (2012). Urgensi Pendidikan dan Pelatihan Kepala Sekolah dalam Upaya Peningkatan Profesionalisme. Jurnal Lentera. Vol. 2. hlm. 3.

${ }^{11}$ Kompas, edisi 12 Juli 2012.
}

kelahiran program pelatihan kepala sekolah yang digagas oleh Sekolah Guru Indonesia (SGI) Dompet Dhuafa yaitu School for Principal (SPc). SGI merupakan salah satu jejaring Divisi Dompet Dhuafa yang berkomitmen melahirkan Guru Transformatif yang memiliki kompetensi mengajar, mendidik, dan berjiwa kepemimpinan sosial. SGI yang berdiri pada Oktober 2009 sudah tersebar di berbagai provinsi, dengan penerima manfaat berjumlah 1.482 orang. SGI memiliki beberapa program, diantaranya adalah Professional Class, Executive Class, School of Master Teacher dan School for Principal.

SPc adalah salah satu wadah untuk meningkatkan kapasitas kepemimpinan kepala sekolah melalui keterampilan managemen sekolah dan supervisi pembelajaran. Program ini berkhidmat untuk meningkatkan kapasitas kepemimpinan kepala sekolah melalui perwujudan pemimpin transformatif dengan karakter 3P (Pendidik, Pengajar, dan Pemimpin). Nilai-nilai jati diri SGI yang tercermin sebagai PEACE (Passion, intEgrity, Affection, Care, and Sinergy), diharapkan dapat menjadi landasan dalam pengembangan kurikulum melalui beragam kegiatan SGI sehingga dapat melahirkan para pemimpin sekolah yang berjiwa pendidik.

Evaluasi penting dilakukan dalam rangka mengetahui seberapa besar tujuan pelatihan tercapai dan mengetahui kekurangan untuk perbaikan di masa depan. $^{12}$ Menurut Sudaryono, evaluasi berarti menentukan sampai seberapa jauh sesuatu itu berharga, bermutu, dan

12 Jejen Musfah. (2011). Peningkatan Kompentensi Guru. Jakarta: Kencana. hlm. 91. 


\section{Evaluasi Program School for Principal...}

bernilai. $^{13}$ Sedangkan menurut Austrian Development Agency and Evaluation Unit bahwa, "evaluation is the systematic and objectives assessment of an on-going or completed project or programme, its design, implementation, and result. ${ }^{14}$

Tujuan paling penting dari sebuah evaluasi program bukanlah untuk membuktikan, tetapi untuk meningkatkan. Namun dalam prakteknya, evaluasi seringkali melibatkan pernyataan atau kesan pelatih maupun peserta. Walaupun sebenarnya hal tersebut tidak terlalu bermanfaat bagi organisasi. Hal yang sesungguhnya ialah apakah pengetahuan yang diperoleh melalui pelatihan akan terlihat pada peningkatan perilaku atau prestasi hasil kerja. Evaluasi seringkali diabaikan bahkan tidak dilakukan, kalaupun diperhatikan hal itu dilakukan secara tidak benar. ${ }^{15}$ Hal tersebut menyebabkan sebuah program yang telah berjalan tidak akan mampu melihat kelemahannya untuk perbaikan program ke depan. Perlu dilakukan evaluasi untuk melihat efektivitas program SPc.

\section{B. METODE PENELITIAN}

Penelitian ini adalah penelitian kualitatif dengan menggunakan pendekatan evaluasi program. Evaluasi kualitatif menggunakan data kualitatif dan untuk menjaringnya menggunakan instrumen kualitatif. Topik atau unit yang akan diteliti dalam penelitian ini adalah context, input, process, dan product dalam penyelenggaraan program School for

13 Sudaryono. (2014). Pengantar Evaluasi Pendidikan. Jakarta: Lentera Ilmu Cendekia. hlm. 6.

14 Austrian Development Agency, and Evaluation Unit. (2008). hlm. 1.

15 Jejen Musfah. (2011). Manajemen Pendidikan: Teori Kebijakan, dan Praktik. Jakarta: Prenada Media Grup. hlm. 96. principal (SPc) wilayah Pandeglang, Banten. Teknik pengumpulan data dilakukan dengan wawancara mendalam dan dokumentasi. Analisis data dilakukan dengan analisis induktif-kualitatif. Penelitian dilaksanakan pada bulan Agustus sampai November 2017. Informan wawancara antara lain dua orang peserta $\mathrm{SPc}$, dua orang fasilitator, dua orang pengelola, dan satu orang pemateri pelatihan. Dokumentasi yang digunakan dalam penelitian ini antara lain data penerima manfaat SGI 22, manual program SPc, CSI (Costumer Satisfaction Indext) dan laporan Program SPe Pandeglang Banten.

\section{HASIL DAN PEMBAHASAN}

Dalam Peraturan Menteri Pendidikan Nasional Republik Indonesia Nomor 13 Tahun 2007 tentang Standar Kepala Sekolah/ Madrasah, terdapat 5 kompetensi yang harus dimiliki oleh seorang kepala sekolah/madrasah di antaranya kepribadian, manajerial, kewirausahaan, dan sosial. Kepala sekolah merupakan pimpinan pendidikan tingkat satuan pendidikan yang menjalankan fungsinya sebagai pemimpin sekaligus manajer sebagaimana mestinya. Kepemimpian pendidikan merupakan bagian esensial dari organisasi pendidikan, bahkan merupakan hal yang sangat urgen dalam berjalannya sebuah organisasi pendidikan. ${ }^{16}$ Sesuai dengan Peraturan Mentri Pendidikan Nasional No. 28 Tahun 2010 tentang Penugasan Guru sebagai kepala sekolah/ madrasah, Bab I Ketentuan Umum Pasal 1, menyatakan bahwa kepala sekolah adalah guru yang diberi tugas tambahan untuk memimpin.

16 Baharuddin dan Umairso. (2012). Kepemimpinan Pendidikan Islam. Yogyakarta: ArRuzz Media. hlm. 77. 
Efektifitas kerja kepala sekolah tergantung pada kemampuan kerjasama dengan seluruh warga sekolah, serta kemampuan mengendalikan pengelolaan sekolah untuk menciptakan proses belajar mengajar. Menurut Jossey, "Effective school leader are strong educator, anchoring their work on central uses of learning and teaching and school improvement. They are moral agents and social advocater for the children and communities they serve." 17

Semakin baik kepala sekolah menerapkan kepemimpinan, semakin tinggi semangat kerja pendidk dalam melaksanakan tugas. ${ }^{18}$ Sebaliknya, semakin rendah kepala sekolah menerapkan kepemimpinan, semakin rendah pula semangat kerja peserta didik dalam melaksanakan tugas-tugas di sekolah. Dengan demikian dapat dikatakan bahwa kepemimpinan sangat berperan dalam meningkatkan semangat kerja guru dalam melaksanakan tugas.

Melihat berbagai tugas dan tanggung jawab kepala sekolah, harus diiringi upaya peningkatan kapasitas dalam memimpin, salah satunya ialah melalui pelatihan. Pelatihan pada dasarnya bermakna sebagai upaya yang dilakukan untuk memperoleh pengetahuan, keterampilan, dan sikap yang dapat digunakan untuk meningkatkan kinerja. ${ }^{19}$ Pelatihan merupakan aktivitas

${ }^{17}$ B. Jossey. (2007). Educational Leadership. USA: Jhon Wiley \& Sons Inc. hlm. 251.

${ }^{18}$ Pusat Pengembangan Tenaga Kependidikan Badan Pengembangan Sumber Daya Manusia Pendidikan dan Kebudayaan dan Penjaminan Mutu Pendidikan Kementrian Pendidikan dan Kebudayaan (2014). Manajemen dan Kepemimpinan Sekolah. Bahan Ajar Implementasi Kurikulum 2013 untuk Kepala Sekolah. Jakarta: Kemendikbud. hlm. 40.

19 Benny Pribadi. (2014). Desain dan Pengmebangan Proses Pelatihan Berbasis Kompetensi. Jakarta: Pranada Media Grup. hlm. 2. yang diprogram untuk meningkatkan keahlian, pengalaman, pengetahuan, atau pembahasan sikap individu. $^{20}$

Menurut Sulaefi, dengan adanya pelatihan dan pengembangan Sumber Daya Manusia, maka suatu organisasi dapat meningkatkan kinerja dan produktivitas karyawannya. ${ }^{21}$ Oleh karena itu, program pelatihan dipandang sebagai sebuah investasi yang berharga yang dapat digunakan dalam menghasilkan SDM yang potensial agar mampu menghadapi arus perubahan yang cepat. $^{22}$ Namun faktanya, menurut Wahjosumidjo, bahwa pada saat ini terlalu banyak program pelatihan yang tidak relevan. Oleh sebab itu, program-program pelatihan yang bermacam-macam harus dikelola secara rapi, menarik, dilaksanakan sesuai dengan daya tarik pada zamannya. ${ }^{23}$

Arikunto menyatakan bahwa terdapat empat macam kebijaksanaan lanjutan setelah evaluasi, di antaranya kegiatan dilanjutkan, dilanjutkan dengan penyempurnaan, dimodifikasi, ataupun tidak dapat dilanjutkan. ${ }^{24}$ Dengan adanya evaluasi program, maka SPc menjadi sebuah refleksi agar dapat diketahui bagaimana tindak lanjut program di masa yang akan datang. Dalam hal ini, evaluasi dilakukan dengan model CIPP (Context, Input, Proces, Produc). Adapun kelebihan

${ }^{20}$ Baharuddin dan Umairso. (2012). hlm. 63.
Sulaefi. (2017). Pengaruh Pelatihan dan Pengembangan terhadap Displin Kerja dan Kinerja Karyawan. Jurnal Manajemen dan Kewirausahaan. Universitas Muhammadiyah Yogyakarta. Vol. 5, No. 1. hlm. 18.

${ }^{22}$ Benny Pribadi. (2014). hlm. 4.

23 Wahjosumidjo. (2010). Kepemimpinan Kepala Sekolah. Tinjauan Teoritik dan Permasalahannya. Jakarta: Rajawali Pers. hlm. 382.

${ }^{24}$ Suharsimi Arikunto. (2006). Dasar-dasar Evaluasi Pendidikan. Jakarta: PT umi Aksara. hlm. 292. 
dari model ini adalah lebih bersifat komprehensif dibandingkan model evaluasi lainnya. ${ }^{25}$ Selain itu, model ini menurut Arikunto dan Cepi sangat tepat dan cocok digunakan untuk mengevaluasi program-program $\quad$ pemrosesan. ${ }^{26}$ Penjabaran masing-masing aspek dijelaskan sebagai berikut:

\section{Aspek Context}

Evaluasi ini mengidentifikasi dan menilai kebutuhan-kebutuhan yang mendasari disusunnya suatu program. Menurut Wang bahwa, "however, context evaluation goes beyond contect definition to incorporate identification of the audience and its needs, as well as comparison of the program's intents with stakeholder requirements". ${ }^{27}$ Peranan kepala sekolah dalam memimpin menjadi tugas yang tidak ringan, terlebih bagi peserta SPc yang sebagian besar memiliki permasalahan yang sama, yaitu tentang pengelolaan SDM. Muara dari sistem sekolah akan selalu mengarah kepada sosok pemimipin karena pusat kendali berada di bawah kekuasaannya. Sebagaimana tugas pemimpin sekolah ialah mengawasi, membenarkan, meluruskan, memandu, menerjemahkan, menetralisasi, mengorganisasikan, dan mentransformasikan kebutuhan dan harapan anggota organisasi. ${ }^{28}$

25 J. Tulung. (2014). Evaluasi Program Pendidikan dan Pelatihan Kepemimpinan di Balai Diklat Keagamaan Manado. Jurnal Acta Diurna. Vol. III, No. 3. hlm. 9.

${ }^{26}$ Suharsimi Arikunto dan Jabar Cepi. (2014). Evaluasi Program Pendidikan: Pedoman Teoritis Praktis bagi Mahasiswa dan Praktisi Pendidikan. Jakarta: PT Bumi Aksara. hlm. 55.

${ }^{27}$ C.X. Victor Wang. (2009). Assessing and Evaluating Adult Learning in Career and Technical Education. China: Zejiang University. hlm. 10.

${ }^{28}$ Iman Machali dan Ara Hidayat. (2016). Education Management. Jakarta: Kencana. hlm. 93.
Pemimpin memiliki tanggung jawab tinggi dan penuh dalam membangun komitmen dan kerjasama dengan semua komponen di sekolah. ${ }^{29}$ Perubahan paradigma pemimpin sekolah menjadi penting dalam menjalankan visi dan misi sekolah. Terlebih adanya kesatuan antara visi guru dan kepala sekolah agar membuat sekolah dapat berkembang menjadi lebih baik ke depannya. Perubahan paradigma berpikir tidak cukup hanya ada di guru saja, namun juga hendaknya ada pada sosok pemimpin sekolah. Program SPc yang diselenggarakan oleh SGI dianggap peserta telah sesuai dengan kebutuhan para kepala sekolah.

Menurut Ulfatin, bahwa setiap organisasi kerja mempunyai kewajiban untuk meningkatkan kualitas sumber daya manusia secara terus menerus dan berkelanjutan, tidak terkecuali kepala sekolah. Di sisi lain mayoritas sekolah SD, SMP, dan SMA tidak melakukan pelatihan guru karena beberapa faktor, di antaranya keuangan, minimnya ide dan konsep, hingga rendahnya kualitas SDM. $^{30}$ Sehingga kebanyakan sekolah hanya mengandalkan program pelatihan yang datang dari pemerintah pusat maupun daerah. ${ }^{31}$ Program SGI muncul untuk menutupi kelemahan tersebut, dan berharap kualitas kepala sekolah dapat membaik.

Tata kelola guru di sekolah masih menjadi permasalahan sebagian besar kepala sekolah di berbagai tempat. Sehingga dengan adanya pelatihan yang mempertimbangkan kebutuhan kepala sekolah, akan membuat pelatihan menjadi

${ }^{29}$ Ginting dan Haryati. (2012).

${ }^{30}$ Ulfatin dan Triwiyanto. (2016). Manajemen Sumber Daya Manusia Bidang Pendidikan. Jakarta: Rajawali Press. hlm. 139.

${ }^{31}$ Jejen Musfah. (2011). hlm. 63. 
lebih bermakna. Di sisi lain, melihat beratnya tugas dan tanggung jawab seorang pemimpin, maka seorang kepala sekolah penting untuk senantiasa meningkatkan kompetensi dan kemampuan dalam memimpin bawahan. Program SPc berperan dalam memperbaiki kualitas kepala sekolah dengan melihat kebutuhan peserta maupun kebutuhan daerah setempat.

\section{Aspek Input}

Menurut Pribadi, bahwa evaluasi input menekankan pada penilaian di aspek perencanaan penyelenggaraan progam pelatihan. ${ }^{32}$ Yahaya mengatakan, "Input evaluation will measure the effort of the system and input from the stategies and the sources. This evaluation is use to arrange result and will be use for giudence in choosing the program strategies and the changes that can be done". 33 Program pelatihan SPe wilayah Banten ini diikuti oleh 28 pemimpin sekolah yang tersebar di 12 Kecamatan yang terdiri dari 16 Sekolah Dasar dan 11 Madrasah Ibtidaiyah. Adapun 12 kecamatan tersebut di antaranya: Menes, Jiput, Cisata, Saketi, Labuan, Banjar, Bojong, Cikeusik, Karang Tanjung, Picung, Panimbang dan Balaraja. Dengan jumlah peserta perempuan sebanyak 10 orang sedangkan peserta lakilaki berjumlah 18 orang. Spesifikasi pendidikan terakhir peserta sebagian besar ialah pada jenjang S1, sedangkan untuk jenjang S2 berjumlah 3 orang. Peserta yang diterima sudah melewati berbagai tahapan seleksi program sebelumnya, di

\section{${ }^{32}$ Benny Pribadi. (2014). hlm. 158.}

${ }^{33}$ Aziz Yahaya. (2001). The Using og Model Kontext, Input, Process and Products (CIPP) in Learning Progams Assessment. Intenational Conference on Callanges and Prospects in Teacher Education. Malaysia: UTM. hlm. 7. antaranya seleksi berkas, wawancara, dan microteaching.

Menurut Kamil, terdapat beberapa hal yang harus diperhatikan dalam pelatihan, di antaranya pelatih, peserta pelatihan, proses pembelajaran, dan bahan pelatihan. ${ }^{34}$ Fasilitator yang berkompeten menjadi bagian yang tidak terpisahkan dari proses perencanaan penyelenggaraan program SPc. Kejelasan job desk antar fasilitator dan keterampilan dalam mengelola program diapresiasi oleh peserta dan pemateri dari luar yang sempat hadir di pelatihan. Ketersediaan tenaga pelatih dengan persentase 50:50 dari luar dan dalam SGI telah sesuai dengan apa yang disampaikan oleh Musfah bahwa, pelaksana pelatihan hendaknya mengundang pembicara dari luar sekolah (organisasi) di samping pembicara dari dalam. $^{35}$ Komposisinya bisa $50 \%$ dari dalam dan $50 \%$ dari luar atau $75 \%$ dari dalam dan $25 \%$ dari luar. Hal ini agar menyeimbangkan antara stimulasi eksternal dan internal. Menurut Pribadi, salah satu karakteristik utama yang harus dimiliki oleh seorang instruktur yang baik adalah menutup program yang memuaskan peserta. $^{36}$ Berdasarkan data hasil CSI (Costumer Satisfication Index) menyatakan bahwa, sebagian besar peserta kurang puas dengan pemateri eksternal, dikarenakan ketidaksesuaian dalam metode penyampaian materi yang cenderung pasif. Berikut ini rincian kegiatan dan narasumber pelatihan.

\footnotetext{
${ }^{34}$ Mustofa Kamil. (2012). Model Pendidikan dan Pelatihan: Konsep dan Aplikasi. Bandung: Alfabeta. hlm. 152.

35 Jejen Musfah. (2011). hlm. 90.

${ }^{36}$ Benny Pribadi. (2014). hlm. 14.
} 


\section{Evaluasi Program School for Principal...}

Tabel 1. Rincian Kegiatan dan Narasumber

\begin{tabular}{|l|c|l|}
\hline \multicolumn{1}{|c|}{ Kegiatan } & Waktu & \multicolumn{1}{c|}{ Narasumber } \\
\hline Stadium Generale & 13 oktober 2016 & Asep Sapa at \\
\hline Military Super Camp & 16 Oktober 2016 & Yonif 320 Gajah Putih \\
\hline Penelitian Tindakan Sekolah & 22 Oktober 2016 & H. Sugeng, M.Pd. \\
\hline Pengembangan Kurikulum & 29 Oktober 2016 & Eutik Sobariyah \\
\hline Supervisi & 5 November 2016 & H. Yoyo Sunaryo, M.Pd. \\
\hline Manajemen Sekolah & 12 November 2016 & Asep Sapa`at \\
\hline Budaya Sekolah & 19 November 2016 & Agung Pardini \\
\hline Training for Trainer & 26 November 2016 & Alumni SMT-SGI \\
\hline Benchmarking & 29 November 2016 & Sekolah Tujuan \\
\hline Sidang PTS & 10 Desember 2016 & Penguji \\
\hline Sumatif dan Learning Community & 17 Desember 2016 & Fasilitator \\
\hline Wisuda & 24 Desember 2016 & Drs. Salman Sunardi, M.Pd. \\
\hline
\end{tabular}

Nilai tertinggi seorang pemimpin ialah terletak pada apa yang dilakukannya menjadi suri tauladan bagi para pengikutnya. ${ }^{37}$ Sikap seorang pemimpin akan menjadi panutan bagi anggota organisasi lainnya. Nilai-nilai lembaga yang diselipkan dalam tata tertib, dikemas dengan baik sehingga peserta merasa program ini menjadi berbeda dari bentuk program-program lainnya yang serupa. Salah satu penanaman nilai dominan dalam pelatihan SPc ialah kedisiplinan waktu dan penanaman karakter. Sehingga hadirlah sebuah budaya disiplin yang tinggi dalam setiap pertemuan. Hal tersebut tampak pada daftar absensi peserta selama masa pelatihan. Kehadiran peserta terhitung sempurna, yaitu sebanyak

${ }^{37}$ Aan Komariah. (2012). Authentic Leadership Kepala Sekolah dalam Menanamkan Sistem Nilai. Jurnal Ilmu Pendidikan. No. 2. hlm. 197.
100\%. Menurut Pribadi, sebuah progam pelatihan harus dapat menciptakan rasa puas dalam diri peserta. Oleh sebab itu, program pelatihan hendaknya efektif, efisien, dan menarik. ${ }^{38}$

Dalam pelaksanaan program SPc, fasilitator membuat berbagai budaya positif bagi para peserta. Berikut ini beberapa gerakan inovasi dan budaya positif yang diinisiasi oleh fasilitator: galonisasi, perpus mini SPc, dan wall gallery. Hal itupun diakui oleh Bapak Ahmad Wahyudin (1 Oktober 2017), bahwa nilai-nilai SGI banyak yang berbekas hingga menjadi contoh bagi kami untuk melakukan hal yang sama di sekolah. Menurut Hao dan Yazdanifard bahwa, "A good culture in the organization not only provides a good working environment for their employees,

\footnotetext{
${ }^{38}$ Benny Pribadi. (2014). hlm. 17.
} 
but also gives a sense of belonging to the employees and increases the commitment". 39 Dengan demikian, dengan adanya budaya positif yang terus tumbuh dan berkembang akan menimbulkan rasa saling memiliki antar peserta dan juga dapat meningkatkan komitmmen bersama.

Program yang memiliki input yang baik, maka akan berdampak pada output yang dihasilkan. Ketersediaan input dalam pelatihan menjadi bagian penting bagi berjalanya sebuah pelatihan. Beberapa hal di antaranya, kehadiran tenaga fasilitator yang telah berpengalaman dalam mengelola program dan tenaga pelatih yang berkompeten, berperan penting dalam keberhasilan program. Namun, dalam pelaksaannya tentu harus lebih berhati-hati. Terlebih dalam menyamakan nilai dan persepsi dengan pihak luar yang belum paham dengan jelas kondisi internal organisasi. Hal ini berdampak pada ketidakpuasan peserta terhadap hal-hal yang belum sesuai dengan standar dan kebutuhan organisas.

\section{Aspek Process}

Menurut Ulfatin bahwa, "perencanaan adalah kegiatan melihat masa depan dalam hal untuk kebijakan, prioritas, biaya dan aktivitas dengan mempertimbangkan kenyataan-kenyataan yang ada". ${ }^{40}$ Dengan kata lain perencanaan dibuat untuk memudahkan proses kegiatan agar dapat berjalan dengan semestinya. Program SPc berjalan sesuai dengan rencana, hal ini terbukti dari bukti dokumen berupa laporan program yang telah dibuat. Laporan program tersebut merangkum

${ }^{39}$ Moo Hao dan Rashad Yazdanifard (2015). How Effective Leadership can Facilitate Change in Organization through Improvement and Innovation. Global Journal of Management and Business Research: A Administrartion and Management. Vol. 15, Issue IX Version I. hlm. 4.

${ }^{40}$ Ulfatin dan Triwiyanto. (2016). hlm. 28. seluruh gambaran kegiatan program yang berhasil dijalankan dengan baik dan lancar. Namun dalam pelaksanaannya tentu tidak terlepas dari berbagai kekurangan, seperti tidak tersedianya diktat perkulihan dan alat observasi dalam proses perkuliahan.

Kegiatan diawali dengan apel pagi. Kegiatan ini berguna untuk membangun disiplin, rasa percaya diri, dan komunikasi antar peserta. Selain itu juga memupuk rasa cinta membaca pada diri guru, karena hal yang disampaikan oleh setiap pembina apel ialah hasil bacaan para kepala sekolah tentang salah satu buku pendidikan. Selain itu juga untuk menambah wawasan, baik dalam ilmu pendidikan maupun nonkependidikan, baik bagi peserta maupun pembina itu sendiri. Hal ini sesuai dengan apa yang disampaikan oleh Musfah, bahwa kepala sekolah harus memiliki kemampuan komunikasi yang baik (interpersonal) dengan bawahan, sehingga tidak terjadi salah paham dalam komunikasi. ${ }^{41}$ Apel pagi berlangsung kurang lebih 30 menit, dengan melibatkan peserta sebagai petugas secara bergantian. Setelah melaksanakan apel pagi, maka peserta segera memasuki ruangan dan segera mengambil makanan yang tersedia. Agenda selanjutnya peserta menulis di catatan tentang apa yang mau dipelajari hari ini dan juga apa yang ingin mereka dapatkan. Catatan tersebut ditempelkan pada Wall Gallery yang telah disediakan sebelumnya.

Setelah selesai, pada pukul 09.00 acara dimulai dengan pembukaan oleh fasilitator berupa info-info atau pengumuman terkait agenda SPc. Setelah itu, fasilitator menyerahkan kepada ketua kelas yang akan memandu kelas hari tersebut. Kemudian langsung masuk ke konten yang akan disampaikan oleh

\footnotetext{
${ }^{41}$ Jejen Musfah. (2015). hlm. 302.
} 
pemateri di hari tersebut. Setelah materi sesi satu selesai dilanjutkan dengan istirahat, sholat, dan makan siang. Lalu untuk menuju ke sesi kedua dibuka kembali oleh ketua kelas. Kemudian, agenda diserahkan kepada pemateri. Setelah materi selesai, fasilitator kembali memberikan arahan atau informasi terkait dengan perkuliahan yang akan datang. SPc Diary, menjadi bagian yang tidak ketinggalan melengkapi agenda program. Terakhir sebelum pulang peserta harus mengisi lembar evaluasi perkuliahan yang telah diselenggarakan.

Aspek nilai-nilai, karakter, dan pembiasaan serta pendekatan personaliti menjadi sebuah kesan tersendiri bagi peserta. Karena pada dasarnya kepala sekolah ialah pusat moral bagi sekolah. ${ }^{42}$ Menurut Kartono, bahwa ada beberapa ciri-ciri sifat negatif yang tidak perlu dimiliki oleh kepala sekolah di antaranya intelegensi rendah, sifat penakut, egois/individualis, infantil (kekanakkanakan), serta tidak bertanggung jawab. ${ }^{43}$ Penanaman nilai dan karakter dalam setiap kesempatan akan memupuk sikap-sikap positif kepala sekolah.

Hal yang masih menjadi hambatan program ialah terkait tindak lanjut pasca program. Menjadi sebuah tantangan untuk membuat peserta tetap bergerak dan berubah meskipun pelatihan sudah selesai. Pengontrolan yang berkala para peserta ikut menjadi hambatan program. Hal yang menjadi bahan pertimbangan lain ialah bagaimana mengukur keberhasilan peserta setelah pelaksanaan program berlangsung,

42 James H. Stronge, dkk. (2011). Kualitas Kepala Sekolah. Jakarta: PT Indeks. hlm. 123.

43 Kartini Kartono. (2011). Pemimpin dan Kepemimpinan. Jakarta: PT RajaGrafindo Persama. hlm. 67. serta tetap memastikan peserta konsisten dengan apa yang ia lakukan.

Pelaksanaan pelatihan yang menjadikan nilai-nilai sebagai landasan kegiatan memiliki kelebihan tersendiri. Jadwal yang terarah, penanaman nilai yang kuat dan adanya konsistensi dalam kedisiplinan waktu menjadi bagian penting dalam membiasakan hal baik pada diri kepala sekolah. Sosok pemimpin sebagai teladan yang digugu dan ditiru oleh para guru dan juga siswa, tentu harus memberikan contoh dan sikap yang baik dalam memimpin. Pembiasaan yang ditanamkan dalam kurikulum tersembunyi SGI ialah dalam rangka membentuk dan membiasakan peserta untuk mejadi pemimpin yang paripurna.

\section{Aspek Product}

Evaluasi produk berfokus pada bagaimana hasil yang telah dicapai selama proses berlangsung. Menurut Yahaya bahwa, "product evaluation focus to the result of the program after it finish". ${ }^{4}$ Selama proses pelatihan, hasil yang dicapai dirangkum dalam perolehan nilai seperti yang digambarkan pada diagram di bawah ini.

\section{Gambar 1. Perolehan Nilai Peserta SPc}

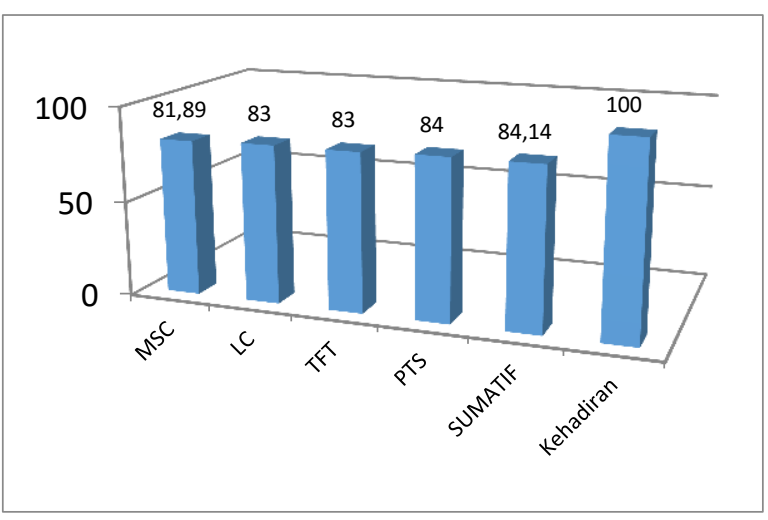

${ }^{44}$ Aziz Yahaya. (2011). The Using og Model Kontext, Input, Process, and Products (CIPP) in Learning Programs Assessment. International Conference on Callanges and Prospects in Teacher Education. Malaysia: UTM. hlm. 10. 
Dari data tersebut dapat dilihat bahwa perolehan nilai rata-rata masing-masing sesi dalam pelatihan, antara lain 81,89 MSC (Millitary Super Camp), 83 LC (Learning Community), 83 TFT (Training for Trainer), 84 PTS (Penelitian Tindakan Kelas), 84 Sumatif dan 100 untuk kehadiran. Selain nilai tes yang diujikan dalam ujian. Kompetensi dalam pedagogik menjadi produk pelatihan, di antaranya ialah PTS, kurikulum sekolah, Banchmarking serta karya tulis. Terdapat beberapa hasil karya yang dibuat oleh para kepala sekolah di antaranya adalah 28 penelitian tindakan sekolah, 4 tulisan "Pena Sang Pemimpin", serta 4 Laporan Benchmarking.

Ketiganya merupakan produk hasil karya para peserta yang dibuat selama proses pelatihan berlangsung. Sedangkan pengukuran tingkat kepuasan peserta yang tertuang dalam hasil CSI (Costumer Satisfaction Index) menunjukkan hasil pada kriteria sangat memuaskan yaitu pada angka $120 \%$.

Menurut Žūkaitè-Jefimovienė (2012: 5) bahwa "Customer satisfaction is the key factor determining how successful an organisation will be in customer relationships; therefore, it is very important to measure it". 45

Tabel 2. Perolehan Tingkat Kepuasan

\begin{tabular}{|c|c|c|c|c|c|c|}
\hline Kode & Kriteria & Harapan & Kenyataan & $\begin{array}{c}\text { Nilai } \\
\text { Serquel }\end{array}$ & $\begin{array}{c}\text { Nilai Aktual } \\
\text { Serquel \% }\end{array}$ & Tingkat Kepuasan \\
\hline A & Seleksi & 4,00 & 5,00 & 1,00 & 125 & Sangat Puas \\
\hline B & Sapras & 3,40 & 4,80 & 1,40 & 141 & Sangat Puas \\
\hline C & Pengelola & 3,60 & 5,00 & 1,40 & 139 & Sangat Puas \\
\hline D & Pengajar & 4,80 & 5,00 & 0,20 & 104 & Sangat Puas \\
\hline E & Metode & 4,89 & 5,00 & 0,11 & 102 & Sangat Puas \\
\hline F & Coach & 4,00 & 4,44 & 0,44 & 111 & Sangat Puas \\
\hline & \multicolumn{7}{|c}{ Kesimpulan } & $\mathbf{1 2 0}$ & Sangat Puas \\
\hline
\end{tabular}

Peserta SPc

Tabel 2. Perolehan Tingkat Kepuasan Peserta SPc

\begin{tabular}{|c|c|c|c|c|c|c|}
\hline Kode & Kriteria & Harapan & Kenyataan & Nilai Serquel & $\begin{array}{c}\text { Nilai Aktual } \\
\text { Serquel } \%\end{array}$ & Tingkat Kepuasan \\
\hline A & Seleksi & 4,00 & 5,00 & 1,00 & 125 & Sangat Puas \\
\hline B & Sapras & 3,40 & 4,80 & 1,40 & 141 & Sangat Puas \\
\hline C & Pengelola & 3,60 & 5,00 & 1,40 & 139 & Sangat Puas \\
\hline D & Pengajar & 4,80 & 5,00 & 0,20 & 104 & Sangat Puas \\
\hline
\end{tabular}

${ }^{45}$ N. Žūkaitè-Jefimovienè (2012). Study On Costomer Satisfaction with Facilities Management Services in Lithuania. Slovak Journal of Civil Engineering. Vol, xx, No. 4. hlm. 5. 


\section{Evaluasi Program School for Principal...}

\begin{tabular}{|c|c|c|c|c|c|c|}
\hline Kode & Kriteria & Harapan & Kenyataan & Nilai Serquel & $\begin{array}{c}\text { Nilai Aktual } \\
\text { Serquel \% }\end{array}$ & Tingkat Kepuasan \\
\hline E & Metode & 4,89 & 5,00 & 0,11 & 102 & Sangat Puas \\
\hline F & Coach & 4,00 & 4,44 & 0,44 & 111 & Sangat Puas \\
\hline \multicolumn{7}{|c|}{ Kesimpulan } \\
\hline
\end{tabular}

Dari data tersebut dapat diketahui bahwa kenyataan lebih besar daripada harapan. Tingkat kepuasan yang tinggi merupakan representatif dari implementasi program yang melebihi harapan yang ada. Tingkat kepuasan tersebut dilihat dari mulai awal proses yaitu seleksi peserta kemudian proses pelatihan, mulai dari sarana dan prasarana, pengelola, pengajaran, metode, hingga pelatih. Sehingga, para pengelola menganggap bahwa program ini memang layak untuk dilanjutkan.

Dari penjelasan sebelumnya, dapat dibuat tebel keunggulan dan kelemahan pelatihan SPc sebagai berikut.

\begin{tabular}{|c|l|l|}
\hline No & \multicolumn{1}{|c|}{ Keunggulan } & \multicolumn{1}{c|}{ Kelemahan } \\
\hline 1 & $\begin{array}{l}\text { Penguatan nilai dan karakter } \\
\text { kepemimpinan kepala } \\
\text { sekolah/madrasah }\end{array}$ & $\begin{array}{l}\text { Tidak semua trainer mampu membudayakan } \\
\text { nilai SGI }\end{array}$ \\
\hline 2 & $\begin{array}{l}\text { Tata tertib dan nilai-nilai yang } \\
\text { mambudaya }\end{array}$ & $\begin{array}{l}\text { Kegiatan pasca program yang belum } \\
\text { terkontrol }\end{array}$ \\
\hline 3 & $\begin{array}{l}\text { Fasilitator menggunakan } \\
\text { pendekatan kekeluargaan }\end{array}$ & $\begin{array}{l}\text { SDM SGI yang masih terbatas terkait } \\
\text { kegiatan kealumnian }\end{array}$ \\
\hline
\end{tabular}

\section{KESIMPULAN}

School for Principle (SPc) merupakan salah satu program Sekolah Guru Indonesia (SGI) yang berfokus pada peningkatan kompetensi kepala sekolah. Program pelatihan nonformal yang berada di bawah naungan Dompet Dhuafa Coorporate University ini diadakan setiap pekan sekali selama tiga bulan. Pelaksanaan program SPc secara umum sudah baik, namun tentu tidak lepas dari berbagai kekurangan yang masih perlu diperbaiki dalam beberapa aspek agar dapat memberikan kebermanfaatan yang luas. Hasil evaluasinya adalah sebagai berikut: Pertama, dalam aspek konteks bahwa program ini dapat menjawab kebutuhan peserta yang sebagian besar terkait dengan pengelolaan guru. Kedua, aspek input, sumber belajar berupa modul belum tersedia dan peningkatan tugas agar materinya dalam. Ketiga, aspek proses, program pelatihan berjalan dengan baik sebagaimana prosedur yang tetapkan sebelumnya. Tetapi belum terlaksana proses yang lebih aplikatif berupa terjun langsung ke lapangan, seperti supervisi langsung oleh fasilitator. Keempat, aspek produk, hasil pencapaian nilai adalah baik (A), menghasilkan 28 penelitian, 4 tulisan, 4 laporan banchmarking, dan juga hasil olah CSI (Costumer Satisfaction Index) dengan kategori sangat memuaskan. 


\section{DAFTAR PUSTAKA}

Arikunto, S. (2006). Dasar-dasar Evaluasi Pendidikan. Jakarta: PT Bumi Aksara.

Baharuddin dan Umairso. (2012). Kepemimpinan Pendidikan Islam. Yogyakarta: Ar-Ruzz Media.

Chairunnisa, C. (2016). Manajemen Pendidikan dalam Multi Perspectif. Jakarta: PT RajaGrafindo Persada.

Fathurrohman, P. (2012). Guru Profesional. Bandung: Refika Aditama.

Ginting dan Haryati. (2012). Kepemimpinan dan Konteks Penigkatan Mutu Pendidikan. Jurnal Ilmiyah CIVIS. Vol. II.

Hao, M. dan Yazdanifard, R. (2015). How Effective Leadership can Facilitate Change in Organization through Improvement and Innovation. Global Journal of Management and Business Research: A Administrartion and Management. Vol. 15, Issue IX Version I.

Hidayat, N. (2012). Urgensi Pendidikan dan Pelatihan Kepala Sekolah dalam Upaya Peningkatan Profesionalisme. Jurnal Lentera. Vol. 2.

Hurriyati, R. (2016). Kualitas Guru Kita. Pikiran Rakyat, diakses 15 Januari 2017.

James H. Stronge, dkk. (2011). Kualitas Kepala Sekolah. Jakarta: PT Indeks.

Jossey, B. (2007). Educational Leadership. USA: Jhon Wiley \& Sons Inc.

Kartono, K. (2011). Pemimpin dan Kepemimpinan. Jakarta: PT RajaGrafindo Persama.

Komariah, A. (2012). Authentic Leadership Kepala Sekolah dalam Menanamkan Sistem Nilai. Jurnal Ilmu Pendidikan. No. 2.
Machali, I. dan Hidayat, A. (2016). Education Management. Jakarta: Kencana.

Musfah, J. (2015). Manajemen Pendidikan Teori, Kebijakan, dan Praktik. Jakarta: Prenada Media Grup.

Musfah, J. (2011). Peningkatan Kompentensi Guru. Jakarta: Kencana.

Pribadi, B. (2014). Desain dan Pengmebangan Proses Pelatihan Berbasis Kompetensi. Jakarta: Pranada Media Grup.

Pusat Pengembangan Tenaga Kependidikan Badan Pengembangan Sumber Daya Manusia Pendidikan dan Kebudayaan dan Penjaminan Mutu Pendidikan Kementrian Pendidikan dan Kebudayaan (2014). Manajemen dan Kepemimpinan Sekolah. Bahan Ajar Implementasi Kurikulum 2013 untuk Kepala Sekolah. Jakarta: Kemendikbud.

Robbins, S. (2015). Perilaku Organisasi. Jakarta Salemba Empat.

Sudaryono. (2014). Pengantar Evaluasi Pendidikan. Jakarta: Lentera Ilmu Cendekia.

Sulaefi. (2017). Pengaruh Pelatihan dan Pengembangan terhadap Displin Kerja dan Kinerja Karyawan. Jurnal Manajemen dan Kewirausahaan. Universitas Muhammadiyah Yogyakarta. Vol. 5, No. 1.

Suratno, T. (2014). Konstrutivisme, Konsepsi Alternatif, dan Perubahan Konseptual dalam Pendidikan IPA. Jurnal Pendidikan Dasar. No. 10 Oktober.

Suharsaputra, U. (2016). Kepemimpinan Inovasi Pendidikan. Bandung: Refika Aditama.

Arikunto, S. dan Cepi, J. (2014). Evaluasi Program Pendidikan. Pedoman Teoritis Praktis Bagi Mahasiswa dan Praktisi Pendidikan. Jakarta: Bumi Aksara. 


\section{Evaluasi Program School for Principal...}

Tilaar, H.AR. (2012). 10 Windu Pendidikan Nasional: Arah ke Mana. Jakarta: PT Kompas Media Nusantara.

Tulung, J. (2014). Evaluasi Program Pendidikan dan Pelatihan Kepemimpinan di Balai Diklat Keagamaan Manado. Jurnal Acta Diurna. Vol. III, No. 3.

Ulfatin dan Triwiyanto. (2016). Manajemen Sumber Daya Manusia Bidang Pendidikan. Jakarta: Rajawali Press.

Umammah. (2009). Pengaruk Kepemimpinan dan Keterampilan Manajerial kepala Sekolah Terhadap Kinerja Guru se-Kabupaten Malang. Malang: UIN Press.

Wahjosumidjo. (2010). Kepemimpinan Kepala Sekolah. Tinjauan Teoritik dan Permasalahannya. Jakarta: Rajawali Pers.

Wang, C.X. Victor. (2009). Assessing and Evaluating Adult Learning in Career and Technical Education. China: Zejiang University.

Yahaya, A. (2011). The Using og Model Kontext, Input, Process, and Products (CIPP) in Learning Programs Assessment. International Conference on Callanges and Prospects in Teacher Education. Malaysia: UTM.

Žūkaitè-Jefimovienè, N. (2012). Study On Costomer Satisfaction with Facilities Management Services in Lithuania. Slovak Journal of Civil Engineering. Vol, xx, No. 4. 